NASA/TM-2001-210817

\title{
Coarse Grid Modeling of Turbine Film Cooling Flows Using Volumetric Source Terms
}

James D. Heidmann

Glenn Research Center, Cleveland, Ohio

Scott D. Hunter

General Electric Aircraft Engines, Evendale, Ohio 
Since its founding, NASA has been dedicated to the advancement of aeronautics and space science. The NASA Scientific and Technical Information (STI) Program Office plays a key part in helping NASA maintain this important role.

The NASA STI Program Office is operated by Langley Research Center, the Lead Center for NASA's scientific and technical information. The NASA STI Program Office provides access to the NASA STI Database, the largest collection of aeronautical and space science STI in the world. The Program Office is also NASA's institutional mechanism for disseminating the results of its research and development activities. These results are published by NASA in the NASA STI Report Series, which includes the following report types:

- TECHNICAL PUBLICATION. Reports of completed research or a major significant phase of research that present the results of NASA programs and include extensive data or theoretical analysis. Includes compilations of significant scientific and technical data and information deemed to be of continuing reference value. NASA's counterpart of peerreviewed formal professional papers but has less stringent limitations on manuscript length and extent of graphic presentations.

- TECHNICAL MEMORANDUM. Scientific and technical findings that are preliminary or of specialized interest, e.g., quick release reports, working papers, and bibliographies that contain minimal annotation. Does not contain extensive analysis.

- CONTRACTOR REPORT. Scientific and technical findings by NASA-sponsored contractors and grantees.
- CONFERENCE PUBLICATION. Collected papers from scientific and technical conferences, symposia, seminars, or other meetings sponsored or cosponsored by NASA.

- SPECIAL PUBLICATION. Scientific, technical, or historical information from NASA programs, projects, and missions, often concerned with subjects having substantial public interest.

- TECHNICAL TRANSLATION. Englishlanguage translations of foreign scientific and technical material pertinent to NASA's mission.

Specialized services that complement the STI Program Office's diverse offerings include creating custom thesauri, building customized data bases, organizing and publishing research results ... even providing videos.

For more information about the NASA STI Program Office, see the following:

- Access the NASA STI Program Home Page at http://www.sti.nasa.gov

- E-mail your question via the Internet to help@sti.nasa.gov

- Fax your question to the NASA Access Help Desk at 301-621-0134

- Telephone the NASA Access Help Desk at 301-621-0390

- Write to: NASA Access Help Desk NASA Center for AeroSpace Information 7121 Standard Drive Hanover, MD 21076 
NASA/TM-2001-210817

\section{Coarse Grid Modeling of Turbine Film Cooling Flows Using Volumetric Source Terms}

James D. Heidmann

Glenn Research Center, Cleveland, Ohio

Scott D. Hunter

General Electric Aircraft Engines, Evendale, Ohio

Prepared for the 2001 Turbo Expo sponsored by the American Society of Mechanical Engineers New Orleans, Louisiana, June 4-7, 2001

National Aeronautics and Space Administration

Glenn Research Center 
This report is a preprint of a paper intended for presentation at a conference. Because of changes that may be made before formal publication, this preprint is made available with the understanding that it will not be cited or reproduced without the permission of the author.

Available from

NASA Center for Aerospace Information

7121 Standard Drive

Hanover, MD 21076
National Technical Information Service 5285 Port Royal Road Springfield, VA 22100 


\title{
COARSE GRID MODELING OF TURBINE FILM COOLING FLOWS USING VOLUMETRIC SOURCE TERMS
}

\author{
James D. Heidmann \\ National Aeronautics and Space Administration \\ Glenn Research Center \\ Cleveland, Ohio 44135 \\ Scott D. Hunter \\ General Electric Aircraft Engines \\ Evendale, Ohio 45215
}

\begin{abstract}
The recent trend in numerical modeling of turbine film cooling flows has been toward higher fidelity grids and more complex geometries. This trend has been enabled by the rapid increase in computing power available to researchers. However, the turbine design community requires fast turnaround time in its design computations, rendering these comprehensive simulations ineffective in the design cycle. The present study describes a methodology for implementing a volumetric source term distribution in a coarse grid calculation that can model the small-scale and three-dimensional effects present in turbine film cooling flows. This model could be implemented in turbine design codes or in multistage turbomachinery codes such as APNASA, where the computational grid size may be larger than the film hole size. Detailed computations of a single row of 35 degree round holes on a flat plate have been obtained for blowing ratios of $0.5,0.8$, and 1.0 , and a density ratios of 1.0 and 2.0 using a multiblock grid system to resolve the flows on both sides of the plate as well as inside the hole itself. These detailed flow fields were spatially averaged to generate a field of volumetric source terms for each conservative flow variable. Solutions were also obtained using three coarse grids having streamwise and spanwise grid spacings of $3 \mathrm{~d}, 1 \mathrm{~d}$, and $\mathrm{d} / 3$. These coarse grid solutions used the integrated hole exit mass, momentum, energy, and turbulence quantities from the detailed solutions as volumetric source terms. It is shown that a uniform source term addition over a distance from the wall on the order of the hole diameter is able to predict adiabatic film effectiveness better than a near-wall source term model, while strictly enforcing correct values of integrated boundary layer quantities.
\end{abstract}

\section{NOMENCLATURE}

$A_{h} \quad$ hole cross-sectional area

$c_{p} \quad$ specific heat

cfl Courant number

d film cooling hole diameter

DR density ratio $=\rho_{d} / \rho_{\text {in }}$ specific internal energy

momentum ratio $=\left(\rho V^{2}\right) d\left(\rho V^{2}\right)_{\text {in }}$

turbulence kinetic energy

blowing ratio $=(\rho \mathrm{V}) \mathrm{d}(\rho \mathrm{V})_{\text {in }}$

Prandtl number

turbulent Prandtl number

updated conservative variable

old conservative variable

gas constant for air

$\begin{array}{ll}R_{\mathrm{q}} & \text { residual } \\ \mathrm{Re} & \text { Reynolds number }\end{array}$

$S$ effective slot width

$S_{\mathrm{q}} \quad$ source term

$\Delta t \quad$ local time step

$\mathrm{T}$ temperature

u $\quad x$ component of velocity

$v \quad y$ component of velocity

$\mathrm{V}$ absolute velocity

$(\mathrm{vol})_{\mathrm{R}}$ residual volume

$(\mathrm{vol})_{S}$ source term volume

w $\quad \mathrm{z}$ component of velocity

$x \quad$ streamwise distance from hole leading edge

y transverse coordinate from hole centerline.

$\mathrm{y}^{+} \quad$ dimensionless grid spacing

$\mathrm{z}$ normal coordinate from wall

$\eta \quad$ film effectiveness

$\rho$ density

$\omega$ dissipation per unit turbulence kinetic energy

\begin{tabular}{ll}
\multicolumn{2}{l}{ Subscripts } \\
aw & adiabatic wall conditions \\
c & coolant conditions \\
in & freestream inlet conditions \\
o & stagnation conditions
\end{tabular}




\section{INTRODUCTION}

As gas turbine inlet temperatures increase in the drive toward higher cycle efficiencies, film cooling of high pressure turbine blades is increasingly needed to ensure their durability. However, film cooling flows are complex three-dimensional flows involving streams of different temperature, and are not easily described using low-order models. In addition, the scale of film cooling flows is much smaller than the scale over which the aerodynamic design of turbine systems is typically performed. Thus film cooling systems have generally been designed using databases of information from detailed studies. However, in order to optimize the aerodynamics and heat transfer of a film-cooled turbine blade, it would be highly desirable to have a model which would account for the detailed effects of film cooling on a coarser grid such as the type used for turbine aerodynamic design. Such an optimization would reduce the amount of cooling flow required by placing the cooling air only where it is required, and reducing overcooling.

Goldstein (1971) summarizes early studies in the area of film cooling. These studies concentrated on slot flows, and film cooling effectiveness values were found to correlate well with the parameter $\mathrm{x} / \mathrm{Ms}$, where $\mathrm{x}$ is the downstream distance, $\mathrm{M}$ is the blowing ratio, and $\mathrm{s}$ is the slot width. This parameter has also been used for discrete hole cooling, with s defined as the effective slot width for the row of holes. However, the physics of discrete hole cooling is quite different from that of a slot. A row of discrete holes typically has a much lower spanaveraged downstream film effectiveness distribution for the same $\mathrm{x} / \mathrm{Ms}$ due to the formation of vortices which allow hot gas to penetrate to the wall. These vortices are of the scale of the hole size, so if a numerical simulation has a spanwise grid spacing greater than the film hole spanwise pitch, as is typical for turbine blade aerodynamic design, their effect is lost. In essence, any such calculation is two-dimensional on the scale of the film holes.

To overcome this problem, several computational studies have computed turbine blade geometries with accurate resolution of the film holes, and in some cases, of the hole pipes and plena as well. Garg and Gaugler (1997) showed the importance of film hole exit profiles. Garg and Rigby (1999) resolved the plenum and hole pipes for a three-row showerhead film cooling arrangement, and Heidmann, et al. (2000) computed the heat transfer for a realistic turbine vane with 12 rows of film cooling holes with shaped holes and plena resolved. Garg (2000) presented results of a full rotating blade with 172 film holes, resolving the film hole exits, but not the hole pipes and plena. These studies are appropriate in the research environment, but are too computationally intensive for turbine design. A simplified model is thus needed.

Many published studies have discussed the physics and presented data for discrete hole film cooling in simplified geometries. The most basic geometry consists of a row of round holes in a flat plate. There is a relatively large body of experimental data for $35 \mathrm{deg}$. round holes with a pitch of 3d (Pedersen, et al., 1977; Foster and Lampard, 1980; Pietrzyk, et al., 1989; Pietrzyk, et al., 1990; Sinha, et al., 1991). This geometry allows for a study of jet lift-off behavior at various blowing ratios and is perhaps the most realistic simplified geometry for turbine film cooling. In addition, the computational study of Leylek and Zerkle (1994) uses this geometry and gives an excellent description of the vortical flows associated with this geometry. The present study will therefore use this geometry in the development of the film cooling model.

A source term model for film cooling flows has been described by Hunter (1998), and implemented in the APNASA code (Adamczyk, 1985). In this model, source terms of mass, momentum, and energy are added at the blade surface to account for the flux of these quantities due to film cooling or other types of injection. The source terms are added at a single computational cell adjacent to the wall at the hole exit location. The typical distance from the wall for the cell adjacent to the wall is $0.015 \mathrm{~d}$ for these wall function-type grids. The source terms are inferred from the known blowing ratio, hole angle, and temperature ratio. However, the flow produced by these source terms behaves as slot flow for targe spanwise grid spacings, because they are applied in a constant manner across the blade span. It is thus the goal of this research effort to develop a model to account for the three-dimensional mixing of discrete hole injection on the coarse grids typical for turbine aerodynamic design. The test of this model will be its ability to predict span-averaged film effectiveness downstream of a row of discrete film holes in a coarse grid calculation.

\section{COMPUTATIONAL METHOD}

The initial approach of the study was to determine the source terms of mass, momentum, energy, and turbulence quantities which must be added in a two-dimensional (slot) calculation to yield the same flow solution as the span-average of a full three-dimensional calculation including the plenum and hole pipe. The geometry of choice is shown in Figure 1. The holes are aligned with the streamwise direction with an inclination angle of $35 \mathrm{deg}$. The hole spanwise pitch is $3 \mathrm{~d}$. The geometry is the same as that of Leylek and Zerkle (1994) and Sinha et al. (1991).

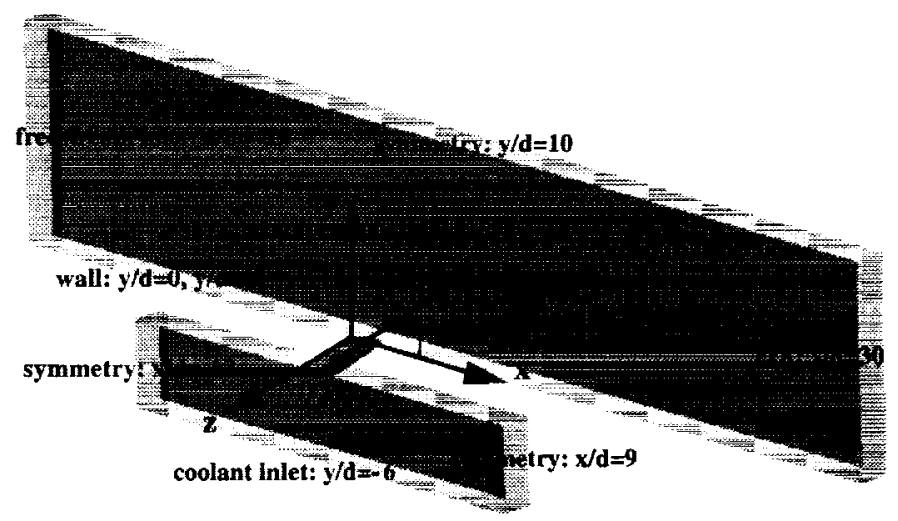

Figure 1: Geometry definition and boundary conditions.

A multi-block computational grid was developed using the GridPro multiblock grid generator with 15 blocks and approximately 162,500 computational cells as shown in Figures 2 and 3. Viscous clustering was employed at all solid walls with $\mathrm{a}^{+}$value less than 1.0 at all locations. Stretching ratios less than 1.2 were used normal to the viscous walls. A second 15 block grid was produced having approximately $1,300,000$ computational cells - twice the number of cells in all three directions. The grid spacing at solid walls was also half that of the first grid. This was done to ascertain the grid dependence of the solutions. Each solution on the initial grid required approximately $10 \mathrm{CRAY}$ C-90 CPU hours to converge. The finer grid required approximately an additional 50 hours to converge, starting from the coarser grid solution. Convergence was considered achieved when both of the following criteria had been met: 1) reduction in all residuals of three orders of magnitude, and 2) no observable change in surface temperature prediction for an additional 200 iterations. It was found that the solution indeed required at least the resolution of the finer grid, since the calculation on the coarser grid underpredicted jet reattachment and film effectiveness. Because of computational limitations, the grid was not refined further. Symmetry 
boundary conditions were employed in the spanwise direction, on all sides of the plenum, and at the $y / d=10$ plane. Fixed mass flow rate and stagnation temperature inlet boundary conditions to the plenum and freestream were used to ensure proper density and blowing ratios. The inlet flows were normal to the inlet planes. Adiabatic no-slip conditions were applied at all solid walls, including the inner surface of the film hole and the plenum. A turbulence intensity of $0.2 \%$ and a turbulence length scale of $10 \%$ of the inlet height were used. The Reynolds number based on hole diameter and inlet conditions was 16100 . An exit boundary condition with fixed static pressure was employed at $x / d=30$. A maximum Mach number not exceeding 0.3 was achieved in the flow field while maintaining the desired Reynolds number by scaling the experimental geometry down by a factor of 5 . This resulted in a hole diameter of $2.54 \mathrm{~mm}$, and was done to allow more rapid convergence of the solution using the density-based formulation of the computer code while minimizing compressibility effects.

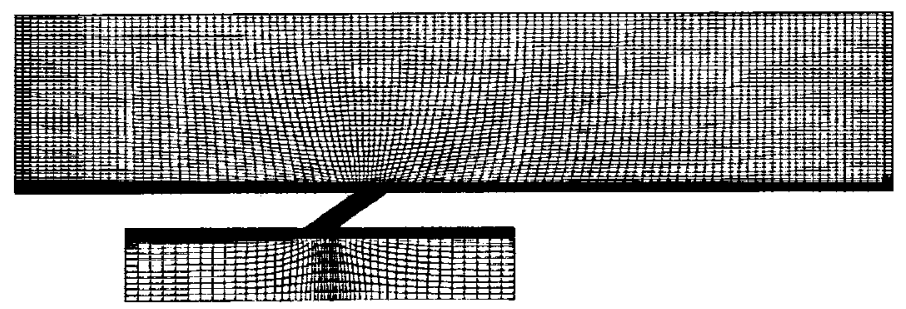

Figure 2: Computational grid at $z=0$.

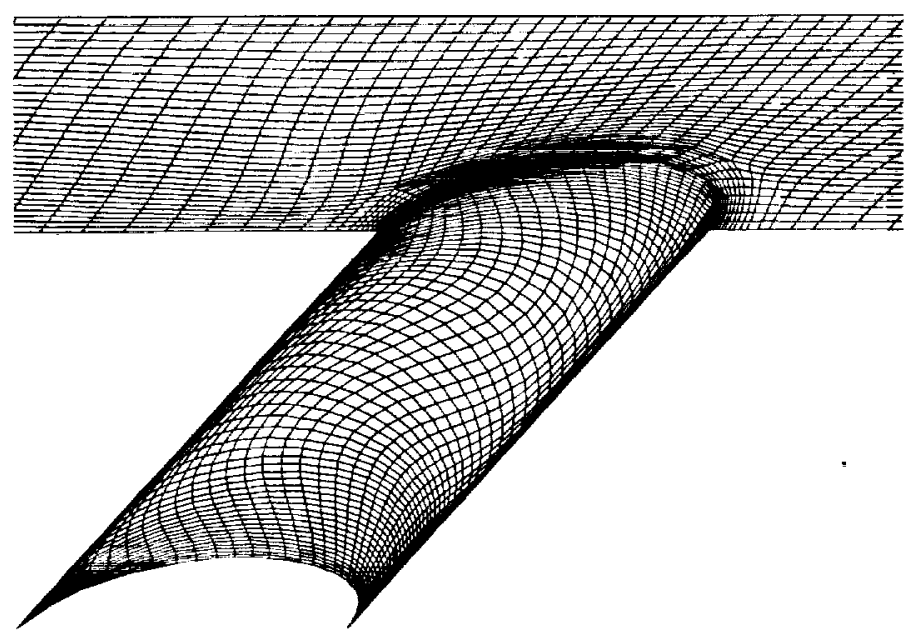

Figure 3: Computational surface grid near hole.

Six numerical simulations were performed for this geometry using different density and blowing ratios. These conditions are shown in Table I. The primary focus of the study is on cases 1-3, for which the density ratio is 2.0 - typical of gas turbine engine operation. The density ratio 1.0 cases were primarily used as a check on source term behavior.
Table I: Detailed Calculation Cases

\begin{tabular}{|c|c|c|c|}
\hline Case & Density ratio & Blowing ratio & Momentum ratio \\
\hline 1 & 2.0 & 0.5 & 0.125 \\
2 & 2.0 & 0.8 & 0.320 \\
3 & 2.0 & 1.0 & 0.500 \\
4 & 1.0 & 0.5 & 0.250 \\
5 & 1.0 & 0.8 & 0.640 \\
6 & 1.0 & 1.0 & 1.000 \\
\hline
\end{tabular}

The simulations in this study were performed using a multiblock computer code called Glenn-HT, previously known as TRAF3D.MB (Steinthorsson et al., 1993) which is based on a single block code designed by Amone et al. (1991). This code is a general-purpose flow solver designed for simulations of flows in complicated geometries. The code solves the full compressible Reynolds-averaged Navier-Stokes equations using a multi-stage Runge-Kutta-based multigrid method. It uses the finite volume method to discretize the equations. The code uses central differencing together with artificial dissipation to discretize the convective terms. The overall accuracy of the code is second order. The present version of the code (Rigby, 1996, Rigby et al., 1997 and Ameri et al. 1997) employs the $k-\omega$ turbulence model developed by Wilcox (1994a, 1994b), with subsequent modifications by Menter (1993) as implemented by Chima (1996). The $\mathrm{k}-\omega$ turbulence model is desirable because it does not require specification of distance to the wall. Such a specification is difficult for complex geometries requiring multi-block grids, such as is considered in the present study. A ccurate heat transfer predictions are possible with the code because the model integrates to the walls and no wall functions are used. Rather, the computational grid is generated to be sufficiently fine near walls to produce a $y^{+}$value of less than 1.0 at the first grid point away from the wall. For heat transfer a constant value of 0.9 for turbulent Prandtl number, $\mathbf{P r}_{t}$, is used. A constant value of $\mathrm{Pr}=0.72$ is used. Laminar viscosity is a function of temperature through a 0.7 power law (Schlichting, 1979) and $c_{p}$ is taken to be a constant.

In order to facilitate the spanwise-averaging of solutions and source terms, the full three-dimensional solutions were interpolated to the cell centers of a rectilinear grid with the same near-wall grid spacing and constant grid spacing in the streamwise and spanwise directions. The rectilinear grid discretized only the region above the plate, since this is the region for which it is desired to match solutions with the model. The quantities interpolated were the conservative variables: density, three components of momentum, energy, turbulence kinetic energy, and dissipation per unit turbulence kinetic energy. The conservative variables were then span-averaged on a volumetric basis to yield a twodimensional flow field that represents the span-average of the full threedimensional flow field above the plate. This is the two-dimensional solution that is desired for the coarse grid solution with the model. This two-dimensional flow field was used as the starting solution for a single Runge-Kutta time step in order to compute the time derivatives of all conservative variables in space. A no-slip boundary condition was used at the hole exit plane. The time derivatives of conservative variables are the quantities that must be subtracted from the residuals at each time step to maintain the desired two-dimensional flow field in time. The negatives of the time derivatives of conservative variables are known as the source terms of these variables. At each time step in the solution, the source terms are added in each conservative equation in the following manner:

$$
\mathrm{q}_{\mathrm{n}}=\mathrm{q}_{\mathrm{o}}+(\mathrm{cfl}) \Delta \mathrm{t}\left[\mathrm{R}_{\mathrm{q}} /(\mathrm{vol})_{\mathrm{R}}+\mathrm{S}_{\mathrm{q}} /(\mathrm{vol})_{\mathrm{S}}\right]
$$


where $q_{n}$ is the updated conservative variable ( $\left.\rho, \rho u, \rho v, \rho w, \rho e, \rho k, \rho \omega\right)$, $q_{o}$ is the conservative variable from the previous iteration, cfl is the global Courant number, $\Delta t$ is the local time step, $R_{q}$ is the local residual for the conservative variable $\mathrm{q},(\mathrm{vol})_{\mathrm{R}}$ is the volume of the computational cell, $S_{q}$ is the source term of the conservative quantity $q$, and (vol $)_{S}$ is the volume of the space over which the source term is applied. In this case, where the source term is defined at each computational cell in the domain, $(\mathrm{vol})_{S}$ is the volume of each computational cell.

The source terms must be corrected for interpolation and discretization error incurred in the process. To do this, source terms for the three-dimensional interpolated flow field were computed, spanaveraged, and subtracted from the original source terms. This process corrects for the nonconservative interpolation process and the different local grid spacing between the two grids. As a check on the correction process, the predicted source terms of mass were found to be zero within machine accuracy. This must be true, because mass must be conserved in the two-dimensional flow field since density was volumetrically spanaveraged. The source term of $\mathrm{z}$-momentum is also zero because the $\mathrm{z}$ component of momentum is zero in the two-dimensional flow field. This leaves $x$ - and $y$-momentum, energy, and the two turbulence quantities as source terms that must be modeled to precisely account for the spanaveraging.

Second and fourth order artificial dissipation were not used in the determination of source terms. This assured that only its direct neighbors determined the source terms at any cell. This also means that the only source terms affected by varying boundary conditions were those for cells immediately adjacent to boundaries. This becomes important at cells next to the film hole inlet. Because it is very difficult to span-average boundary conditions exactly, a jump in the source terms was sometimes noted at these cells. It was decided to ignore these cells, since we are primarily interested in a model of the source terms which varies smoothly as it approaches the boundary. In fact, the source terms are found to be smooth except at the boundary cell. In addition, we are interested in the source terms that arise due to span-averaging in the flow field. The source term model of Hunter (1998) models the source terms that arise due to addition of flow at the boundary.

\section{COMPUTATIONAL RESULTS}

Figure 4 shows the computed hole centerline profiles of stagnation temperature for cases 1-3: density ratio of 2.0 and blowing ratios of 0.5 , 0.8 , and 1.0 . It can be seen that the colder jet fluid penetrates deeper into the freestream as the blowing ratio increases. This is accompanied by an increase in entrained hot freestream fluid under the coolant jet, particularly in the first few hole diameters downstream of the hole trailing edge. This is in contrast to the stagnation temperature profile for a two-dimensional slot. In a two-dimensional calculation, the colder jet fluid is pushed much closer to the wall by the freestream because of the inability of the freestream to penetrate the slot flow. This difference in behavior increases with blowing ratio. The difference in coolant flow trajectory is responsible for a much higher span-averaged film effectiveness in a two-dimensional slot calculation for the same global blowing parameters, as described by Goldstein (1971) and many others. It may also be noted that, particularly for the higher blowing ratio cases, the increase in stagnation temperature along the jet centerline is not monotonic. That is, an island of relatively cool fluid appears downstream of the jet exit. This is due to the vortical nature of the flow. The cool region is actually the cool jet core, which has been swept away from the hole centerline by a pair of counterrotating vortices, and is brought back to the centerline further downstream. Figure 5 shows the appearance of these vortices for cases 1-3. It can be seen that the jet lift-off behavior increases with blowing ratio as the increased strength of the counterrotating vortices enhances entrainment of the hot freestream under the cool jet. In fact, the coolant jet core has actually been divided into two at the highest blowing ratio of 1.0 as the vortices push hot gas up through the center of the jet.
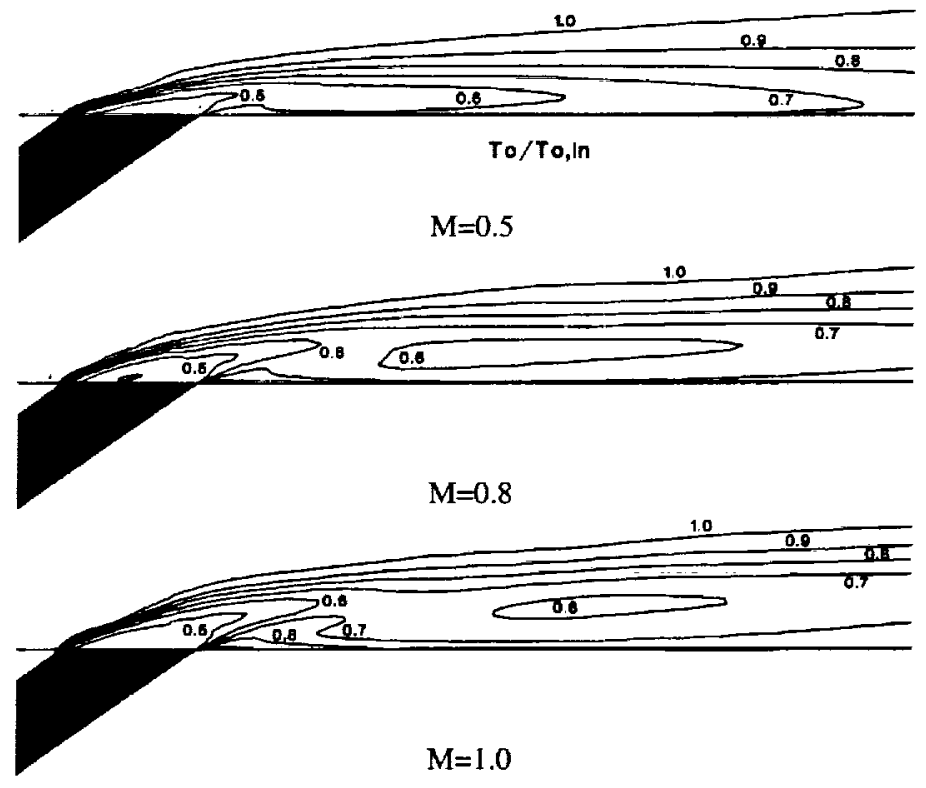

Figure 4: Computed centerline stagnation temperature contours, DR=2.0.

Film effectiveness for a low Mach number flow may be defined as:

$$
\eta=\frac{T_{o, i n}-T_{a w}}{T_{0, i n}-T_{c}}
$$

Figure 6 shows comparisons of the computed span-averaged film effectiveness with the data of Sinha et al. (1991) for cases 1-3. The computations capture the reduction in film effectiveness with increased blowing ratio that results from the increased entrainment and jet lift-off. The computations predict a sharp minimum in effectiveness at the film hole trailing edge $(x / d=1.74)$, and a rapid increase until about $x / d=5$, which corresponds to jet reattachment. This sharp minimum is not reflected in the experimental data, but it may be missed due to the sparseness of the data. The experimental peak effectiveness occurs further downstream for the two higher blowing ratio cases. The crossover in experimental effectiveness between the two lower blowing ratio cases at $x / d=10$ is hinted at in the computation, but also appears further downstream. In general, however, the agreement with experimental data is very good for computational film cooling, which is known to suffer from the presence of anisotropy not modeled by the present turbulence model,

As described in the computational method section, the detailed three-dimensional solutions were span-averaged and the source term distributions required to maintain the span-averaged solution in a twodimensional solution were computed. Figure 7 shows a vector plot of the momentum source terms for case 1. The source terms of momentum are 


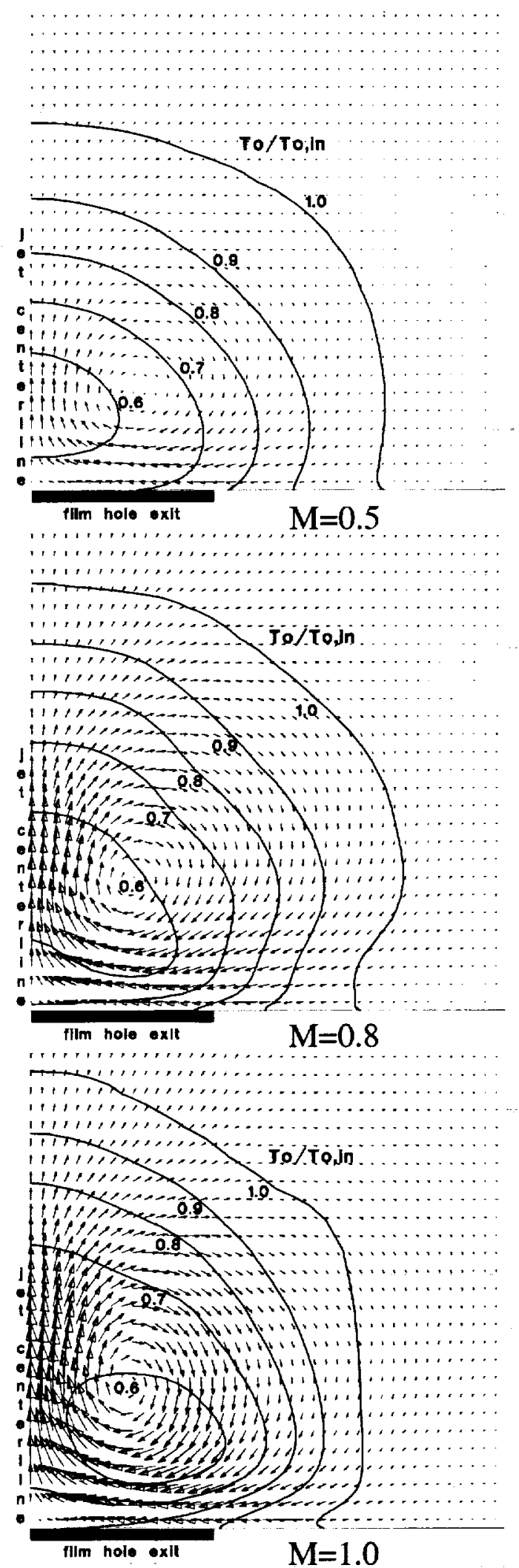

Figure 5: Crossflow vectors and stagnation temperature contours for $D R=2.0, x / d=5.0$.

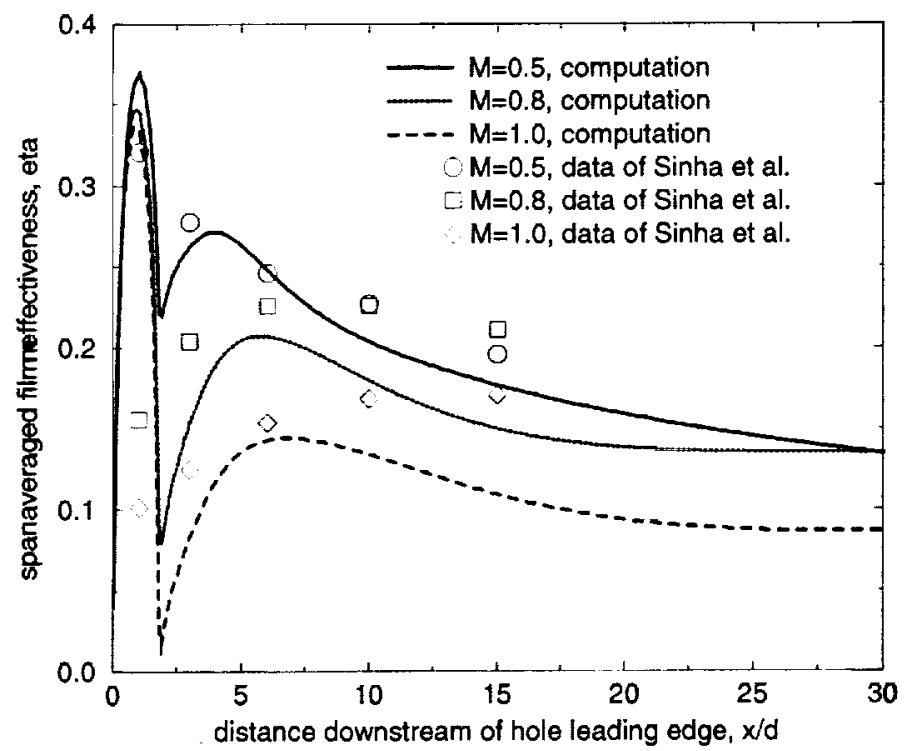

Figure 6: Comparison of computed span-averaged effectiveness with data of Sinha et al. (1991).

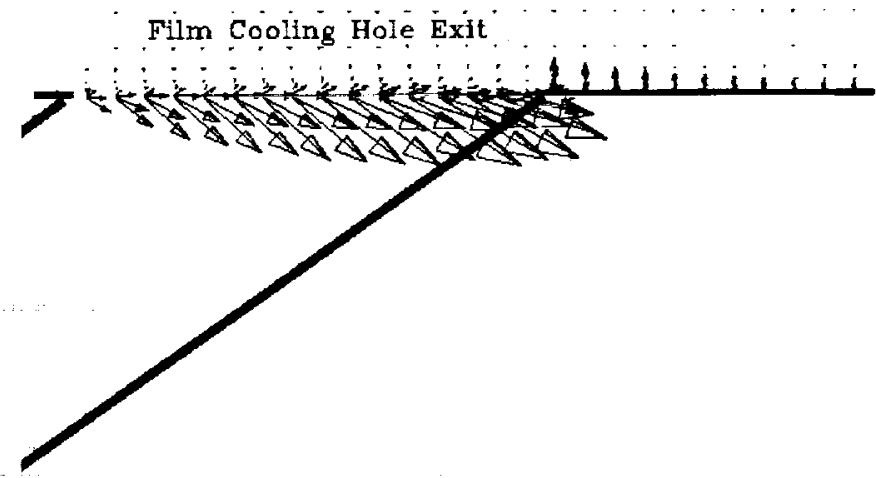

Figure 7: Momentum source term vectors computed from span-average of full 3-D flow field, $D R=2.0, M=0.5$.

highest near the hole exit, and are generally positive in the $\mathrm{x}$ direction and negative in the $y$ direction. It should again be noted that these values are at least two cells from the inlet, and thus unaffected by the boundary condition at the wall. In fact, the direction of the momentum source vector is different from that of the momentum vector itself at the boundary. This source term makes intuitive sense, because a slot flow disrupts the freestream much more than a row of discrete holes with the same gross flow properties. While the discrete jets may themselves penetrate deeper into the freestream, the span-average of this flow is much more aligned with the freestream than the slot flow. The momentum source terms are in the right direction to flatten the jet as it is predicted on a coarse grid. Downstream of the hole, there is a momentum source term away from the wall, which decays slowly in the streamwise direction.

The source terms of energy are shown in Figure 8. Unlike the momentum source terms, the maximum residuals occur away from the 
wall in the upstream interaction zone of the jets with the freestream. This is again due to the penetration of the discrete jets into the mainstream. Referring to Figure 4, the stagnation temperature is lower near the forward edge of the jet due to its penetration than it would be for twodimensional slot flow. This results in a negative source term of energy in this interaction zone. A positive source term of energy exists immediately downstream of the hole exit, where in the three-dimensional solution the stagnation temperature increases due to hot freestream fluid entrainment.

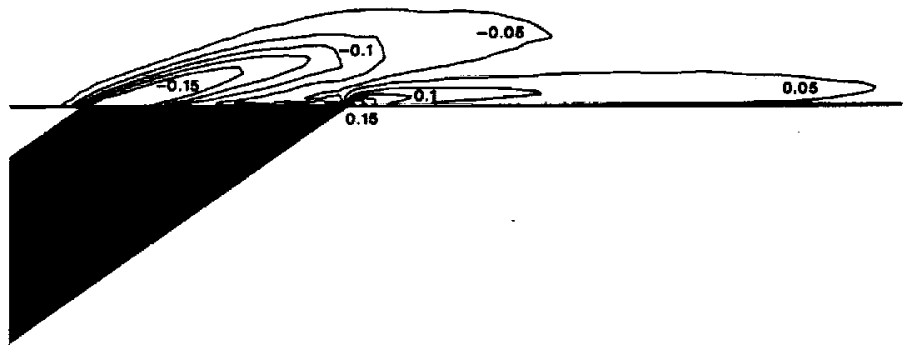

Figure 8: Energy source term contours computed from span-average of full 3-D flow field, $D R=2.0, M=0.5$.

The energy source terms are consistent with the vortical structure of the film cooling flow as shown in Figure 5. These results agree with previous experimental data of Pietrzyk (1989) and calculations by Leylek and Zerkle (1994), as all three show the counterrotating vortex structure downstream of the hole. As the freestream encounters the film cooling jet, it is entrained in the counterrotating vortex structure and moved away from the centerline of the jet. This allows colder jet fluid to displace the hotter freestream fluid. However, the span-averaged $y$-momentum does not reflect this penetration due to the motion of the opposite edge of the vortex, which is downward. Thus a negative source term of energy arises to model the jet penetration in the absence of convective motion in the span-average. Since the goal of this snudy is to model the adiabatic wall temperature downstream of the film cooling holes, it is very important to model the hot fluid entrainment which gives rise to the energy source terms.

A consequence of the preceding explanation is that the energy source terms will depend strongly on the temperature ratio (or, equivalently for single constituent flows, on the density ratio). To test this hypothesis, cases 4-6 was computed, having the same blowing ratios as cases 1-3, but with coolant temperature equal to the freestream (density ratio of 1.0). It was found that the momentum source term distributions are very similar to the comesponding cold jet cases, while the energy source terms are nearly zero. This data indicates that the energy source terms are caused by the temperature difference between the coolant and the freestream.

\section{MODELING}

When the precise source term fields were applied in their entirety to the two-dimensional solution, the exact span-average of the full threedimensional solution was recovered. This is of course expected, because they are functionally defined in this manner. However, this model is too complex since it requires detailed descriptions of all 7 unknowns: density, three components of momentum, energy, and two turbulence model unknowns. Even when the span-averaging is done conservatively, which drops the mass source term, and z-momentum is dropped because the span-averaged $z$-momentum is identically zero over a hole pitch, there are still 5 source term fields to model. A first attempt to reduce the complexity of the model was to ignore turbulence variable source terms. But even with exact representations of the momentum and energy source terms, the adiabatic film effectiveness downstream of the hole was completely different in the two-dimensional case. Several other attempts at simplified models indicated that anything less than full source term modeling resulted in poor representation of the three-dimensional effect.

Because of these difficulties, a different tack was taken. The turbine heat transfer community is primarily concerned with the wall temperature downstream of the film hole. The problem with the existing source term model is that for spanwise grid spacings larger than the film hole pitch, the model represents a slot and overestimates film effectiveness. This is because the source terms are added only at the cell adjacent to the wall. For a design calculation using wall functions, this would correspond to a distance of about $0.015 \mathrm{~d}$ from the wall. Clearly, this will underestimate the jet penetration and mixing. Even for coarse grids fine enough to resolve the spacing between holes (spacings on the order of hole diameter), the streamwise vorticity will be underpredicted in the calculation, leading to overprediction of film effectiveness.

A simple way to overcome these difficulties is to distribute the source terms of mass, momentum, energy, and turbulence quantities over a thicker layer - on the order of the hole diameter - rather than on the order of one wall function grid cell $(0.015 \mathrm{~d})$. This would have the benefit of accounting for the jet penetration and mixing that the coarse grid calculation cannot resolve due to its inability to capture the vorticity which produces it. This approach is akin to the penetration length approach of Dahlander (1998) and Holmer et al. (2000). While Dahlander (1998) recommended a penetration length of Md, Holmer et al. $(2000)$ found their best agreement for realistic conditions with a penetration length of $1.0 \mathrm{~d}$. For the present study, a distributed source term layer of $1.0 \mathrm{~d}$ is used. It is expected that the problems with the existing source term model would become more pronounced at larger grid spacings, especially as the spanwise grid spacing exceeds the hole pitch. For this reason, a series of calculations were performed with Glenn-HT for the flat plate with 35 degree hole with three constant spanwise and streamwise grid spacings: $3 d, 1 d$, and $d / 3$. Only the flow domain above the plate was modeled. The grid spacing normal to the wall of $y^{+}<1.0$ was maintained from the detailed grid. The integrated source terms of mass, momentum, energy, and turbulence quantities were found from integration of the hole exits fluxes of these quantities from the detailed calculations, and are shown in Table II. Referring to Equation (1), ( $\mathrm{vol})_{S}$ is now the volume over which the source terms are applied per hole. For example, for the $3 \mathrm{~d}$ grid with the Id source term layer, the volume per hole is $3 \mathrm{~d} \times 3 \mathrm{~d} \times 1 \mathrm{~d}$, or $9 \mathrm{~d}^{3}$. The quantities in Table II have been normalized by the appropriate average inlet flow quantities and hole length scales to facilitate application to new cases. It can be seen that the mass and energy fluxes scale linearly with blowing ratio, as expected. The other quantities follow a higher order relation.

Figures 9-11 show the effect of adding source terms uniformly over a distance from the wall of $1 \mathrm{~d}$ ( 32 cells from the wall on the current grid) at the hole centerline grid cell location versus the near-wall model of one computational cell on a wall function grid $(0.015 \mathrm{~d}$, or 10 cells from the wall on the current grid) for coarse grids having streamwise and transverse cell sizes of $3 d, 1 d$, and $d / 3$, respectively. All three figures are for case $3, D R=2.0, M=1.0$. This case was chosen because it has the highest level of vorticity, entrainment, and jet lift-off. The results are representative of cases 1 and 2 as well. For the two finer grids (1d and $\mathrm{d} / 3$ ), the source terms were only added in cells which lay above the actual hole exit, so these cases did have some spanwise nonuniformity, unlike 
Table II: Integrated Source Terms $\left(S_{n}\right)$ Per Hole for Cases 1-3, DR=2.0

\begin{tabular}{|c|c|c|c|}
\hline Blowing Ratio (M) & 0.5 & 0.8 & 1.0 \\
\hline mass flux & $0.494(\rho V)_{\text {in }} A_{h}$ & $0.794(\mathrm{pV})_{\mathrm{in}} \mathrm{A}_{\mathrm{h}}$ & $0.997(\rho \mathrm{V})_{\text {in }} A_{h}$ \\
\hline$x$-momentum flux & $0.162\left(\rho V^{2}\right)_{\text {in }} A_{h}$ & $0.364\left(\rho V^{2}\right)_{i n} A_{h}$ & $0.544\left(\rho V^{2}\right)_{\text {in }} A_{h}$ \\
\hline $\mathrm{y}$-momentum flux & $0.082\left(\rho V^{2}\right)_{\text {in }} A_{h}$ & $0.200\left(\rho V^{2}\right)_{\text {in }} A_{h}$ & $0.312\left(\rho V^{2}\right)_{\text {in }} A_{h}$ \\
\hline z-momentum flux & 0 & 0 & 0 \\
\hline energy flux & $0.640(\rho V)_{i n} R T_{i n} A_{4}$ & $1.023(\rho \mathrm{V})_{\mathrm{in}} R \mathrm{~T}_{\mathrm{in}} \mathrm{A}_{\mathrm{h}}$ & $1.281(\rho V)_{i n} R T_{i n} A_{h}$ \\
\hline $\begin{array}{c}\text { turbulence kinetic } \\
\text { energy flux }\end{array}$ & $0.000540\left(\rho \mathrm{V}^{3}\right)_{\text {in }} \mathrm{A}_{\mathrm{h}}$ & $0.000915\left(\mathrm{pV}^{3}\right)_{\text {in }} \mathrm{A}_{\mathrm{h}}$ & $0.001741\left(\rho V^{3}\right)_{i n} A_{h}$ \\
\hline $\begin{array}{l}\text { dissipation per unit } \\
\text { turbulence kinetic } \\
\text { energy flux }\end{array}$ & $1.87\left(\rho V^{2}\right)_{\text {in }} d$ & $4.49\left(\rho V^{2}\right)_{\text {in }} \mathrm{d}$ & $6.91\left(\rho \mathrm{V}^{2}\right)_{\text {in }} \mathrm{d}$ \\
\hline
\end{tabular}

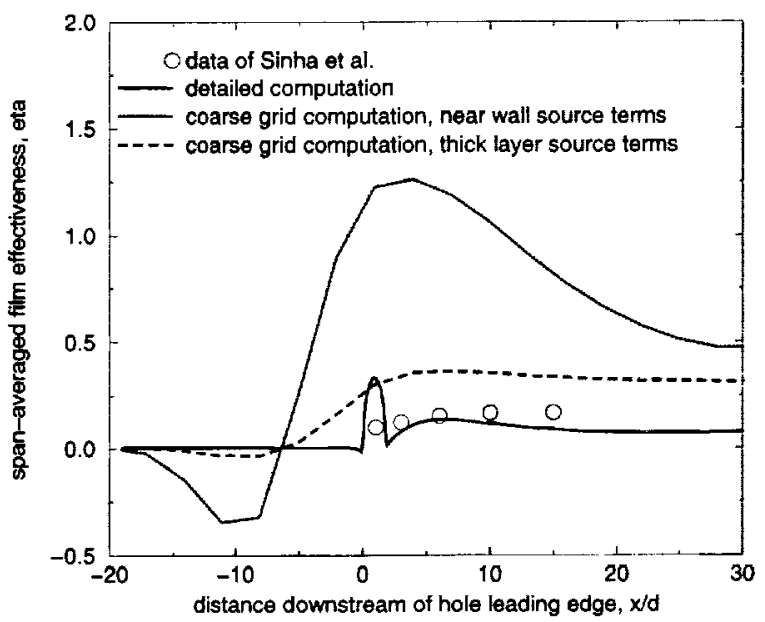

Figure 9: Comparison of span-averaged effectiveness for 2 source term models, grid spacing=3d, $D R=2.0, M=1.0$.

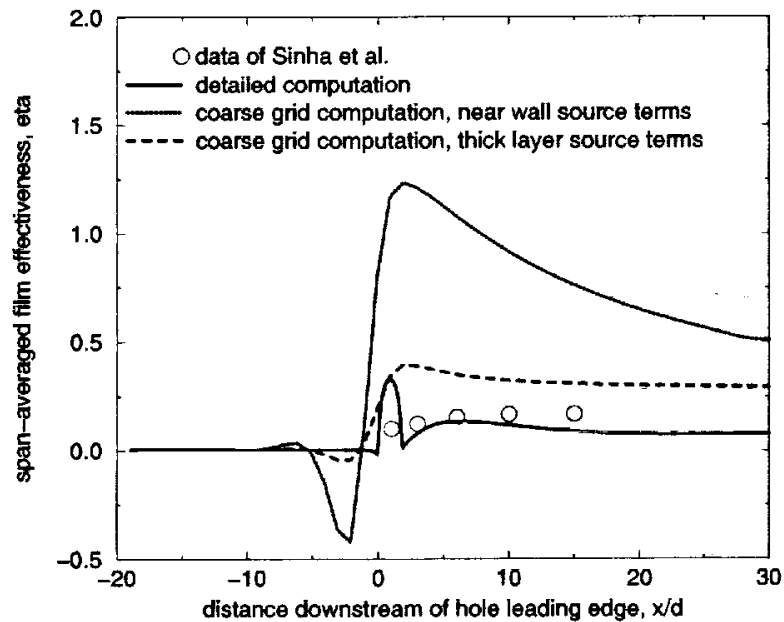

Figure 10: Comparison of span-averaged effectiveness for 2 source term models, grid spacing $=1 d, D R=2.0, M=1.0$.

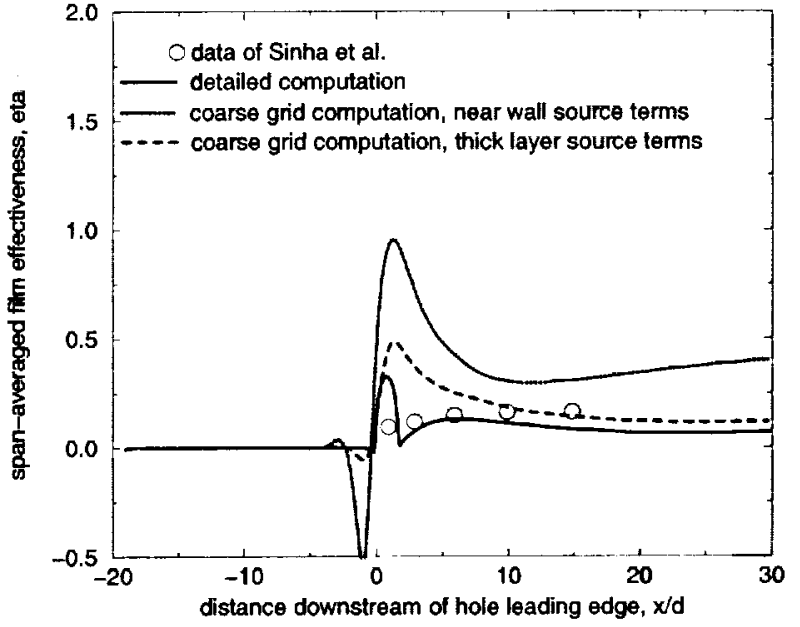

Figure 11: Comparison of span-averaged effectiveness for 2 source term models, grid spacing=d/3, $D R=2.0, M=1.0$.

the coarsest grid (3d). The standard no-slip wall boundary condition was applied at all wall locations, including over the hole exit. It can be seen that for all three grids the near-wall source term model grossly overpredicts film effectiveness downstream of the hole due to the unrealistic introduction of the coolant source terms so close to the wall. This makes intuitive sense, because the near-wall model squeezes all the coolant into a very thin region at the wall. The coarse grids are not fine enough to capture the vorticity that allows the three-dimensional flow to advect from the wall, so the coolant remains too close to the wall and produces film effectiveness predictions which are too high. The nearwall model does slightly better on the finest coarse grid (d/3, Figure 11) because some of the three-dimensional effects are beginning to be predicted, but the distributed source term model is still needed to better model the entrainment effect. The near-wall solutions also exhibit a large overshoot in the temperature at the wall just upstream of the hole. The distributed source term solutions exhibit this overshoot as well, but to a much lesser degree. This is due to Gibbs phenomenon (Foster and Richards, 1991), where an overshoot results from the discontinuous application of source terms. The problem is much worse in the near-wall model due to the much higher source terms per unit volume. 
Figures 12-14 show the effect of grid spacing on the thick source term model implementation for cases $1-3$, respectively. The finest grid (d/3) better matches the downstream $(x / d>5)$ behavior of the data and detailed calculation, but overpredicts the effectiveness near the hole $(\mathrm{x} / \mathrm{d}$ $<5$ ). This is due to the inability of the model to capture the jet detachment that causes the lower effectiveness values in the data and detailed calculation. This might be remedied through a more realistic distribution of source terms, instead of the uniform distribution of the present model. However, such an improvement would be at the expense of the simplicity of the present model, since it would require knowledge of the distribution of the source terms for various blowing ratios. The coarser grids ( $3 \mathrm{~d}$ and Id) actually better predict the near-hole film effectiveness. This is because their source term additions are not as large per unit volume, resulting in a coolant profile that is more evenly distributed. This indicates that the distributed source term model loses some of its advantages as the grid becomes finer. It is expected that as the grid approaches the resolution of the detailed three-dimensional grid, the near-wall source term model would surpass the distributed source term model in predictive capability due to the increased ability to resolve the vorticity. However, it appears that for grids having streamwise and transverse cell sizes on the order of the film cooling hole diameter or larger, the distributed source term model greatly improves upon the nearwall model. The inability of the distributed source term model to match the highest blowing ratio case is a result of the absence of downstream vortex modeling. The finest grid ( $d / 3$ ) does capture this effect far downstream, but all grids fail near the hole, due to the strong jet separation for the highest blowing ratio. Thus it appears that volumetrically-uniform source term models are better suited for lower blowing ratio cases where jet separation is not the dominant feature.

\section{SUMMARY AND CONCLUSIONS}

Detailed calculations have been performed for a flat plate with a row of $35 \mathrm{deg}$. round holes at blowing ratios of $0.5,0.8$, and 1.0 , and density ratios of 1.0 and 2.0. The results were compared with experimental data of Sinha et al. (1991). Some of the local phenomena are not corroborated, but in general the predictions are in very good agreement with the data, especially considering the known difficulty in predicting film effectiveness values for film cooling. The detailed results were then used to compute the source term distributions of mass, momentum, energy, and turbulence quantities resulting from the span-averaging of this highly three-dimensional flow field. It was shown that exact implementation of these source term fields indeed produces the desired result: a two-dimensional calculation of the film-cooled plate on a coarse grid that matches the span-averaged three-dimensional solution. However, this exact implementation is impractical since the source term distribution can only be found by first performing the detailed solution. In addition, implementation of simplified source term distributions failed to adequately match the span-average of the detailed solution.

The near-wall source term model of Hunter (1998) is shown to accurately model the global addition of mass, momentum, energy, and turbulence quantities, but to overpredict film effectiveness due to the underprediction of vortical flows and hot freestream gas entrainment on grids having streamwise and transverse grid spacings on the order of the hole diameter or larger. A source term model is proposed which better predicts the adiabatic film effectiveness downstream of the film holes by uniformly distributing the source term addition over a thicker layer - on

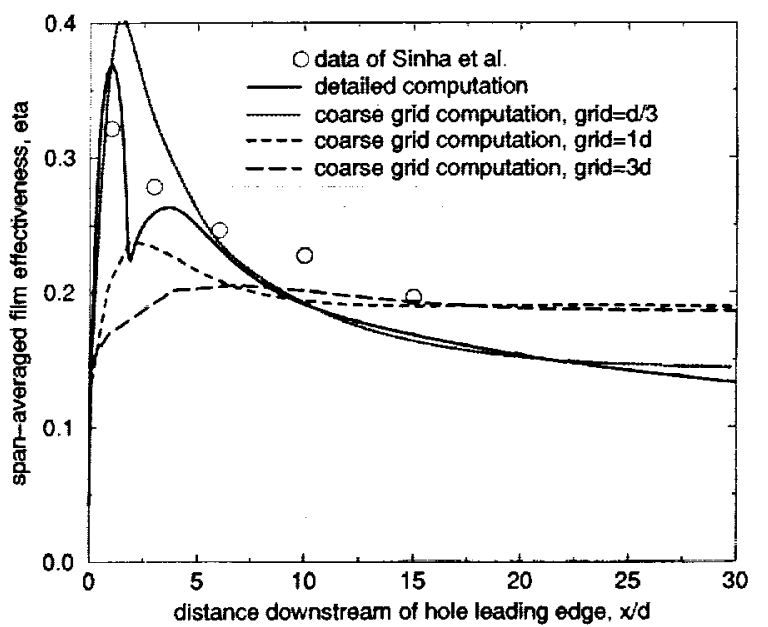

Figure 12: Comparison of span-averaged effectiveness for 3 grid spacings, thick source term model, $D R=2.0, M=0.5$.

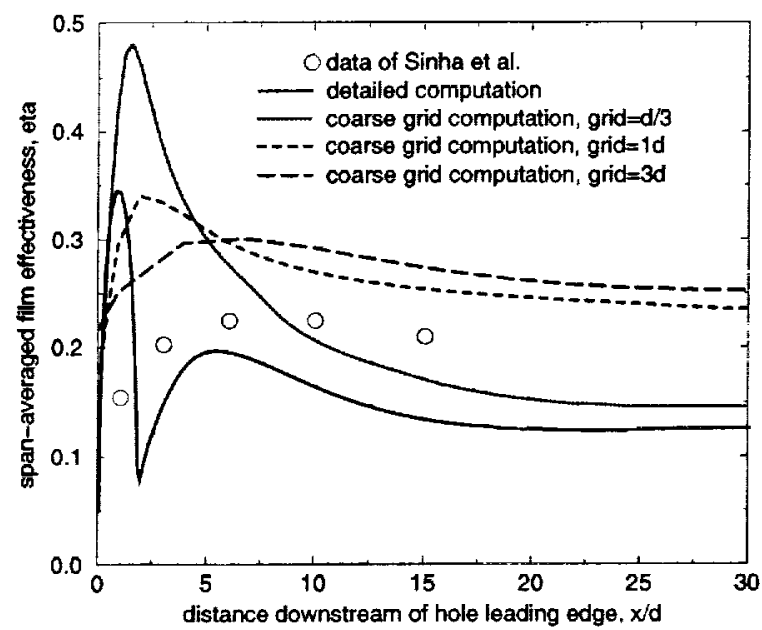

Figure 13: Comparison of span-averaged effectiveness for 3 grid spacings, thick source tem model, $D R=2.0, M=0.8$.

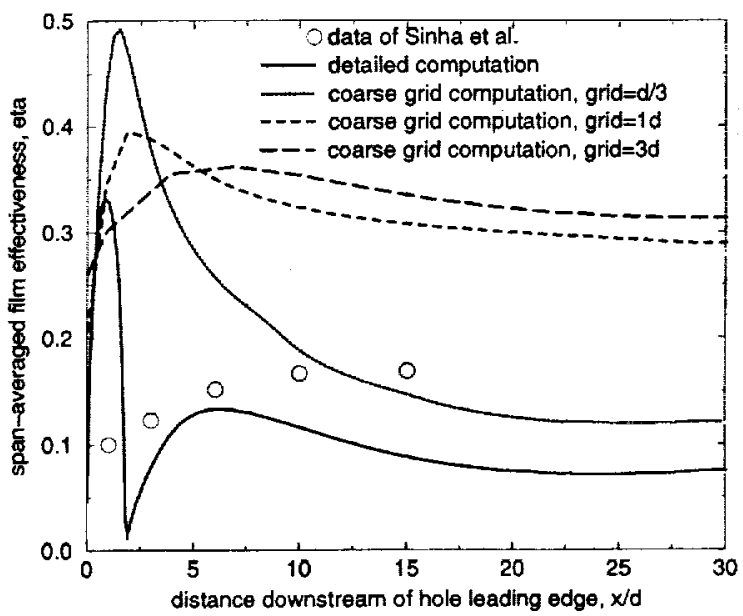

Figure 14: Comparison of span-averaged effectiveness for 3 grid spacings, thick source term model, $D R=2.0, M=1.0$. 
the order of the hole diameter. It is found that the new model provides a much better prediction of film effectiveness downstream of the film hole, while maintaining global conservation of all quantities. The model performs best for lower blowing ratios (attached jets), since the jet detachment behavior is not explicitly modeled. It is also shown that the distributed source term addition performs best on grids having streamwise and transverse grid spacings on the order of the hole diameter or larger, such as those used for engineering design. Finer grids are expected to progressively favor the near-wall source term implementation of Hunter (1998) due to their ability to resolve the vortical flows that produce hot gas entrainment.

Future work in this area will focus on more realistic descriptions of the coolant boundary layer profile in conjunction with downstream entrainment models to model the effect of the downstream vortices which coarse grids cannot resolve. However a more realistic description of the coolant boundary layer profile at the hole exit - in the absence of a downstream mixing model - may actually worsen film effectiveness predictions compared to the current model due to a lower minimum jet temperature and lack of entrainment.

\section{REFERENCES}

Adamczyk, J. J., 1985, "Model Equation for Simulating Flows in Multistage Turbomachines", ASME Paper 85-GT-226.

Ameri, A. A., Steinthorsson, E., and Rigby, D. L., 1997, "Effect of Squealer Tip on Rotor Heat Transfer and Efficiency", ASME Paper 97GT-128.

Arnone, A., Liou, M.-S., and Povinelli, L. A., 1991, "Multigrid Calculation of Three-Dimensional Viscous Cascade Flows", AIAA Paper 91-3238.

Chima, R. V., 1996, "A k- $\omega$ Turbulence Model for Quasi-Three-

Dimensional Turbomachinery Flows”, NASA TM-107051.

Dahlander, P., 1998, “An Engineering Tool for Film Cooling

Simulations", Thesis for the Degree Licentiate of Engineering 98/10,

Department of Thermo and Fluid Dynamics, Chalmers University of Technology, Goteborg, Sweden.

Foster, J. And Richards, F. B., 1991, "The Gibbs Phenomenon for Piecewise-Linear Approximation", American Mathematics Monthly, Vol. 98, pp. 47-49.

Foster, N. W. and Lampard, D., 1980, "The Flow and Film Cooling Effectiveness Following Injection Through a Row of Holes", Journal of Engineering for Power, Vol. 102, pp. 584-588.

Garg, V. K. and Gaugler, R. E., 1997, "Effect of Velocity and

Temperature Distribution at the Hole Exit on Film Cooling of Turbine

Blades", Journal of Turbomachinery, Vol. 119, pp. 343-351.

Garg, V. K. and Rigby, D. L., 1999, "Heat Transfer on a FilmCooled Blade - Effect of Hole Physics", Int. J. Heat and Fluid Flow, Vol. 20, pp.10-25.

Garg, V. K., 2000, "Heat Transfer on a Film-Cooled Rotating

Blade", Int. J. Heat and Fluid Flow, Vol. 21, pp. 134-145.

Goldstein, R. J., 1971, Film Cooling, Advances in Heat Transfer,

Vol. 7, pp. 321-379.

Heidmann, J. D., Rigby, D. L., and Ameri, A. A., 2000, "A Three-

Dimensional Coupled Internal/External Simulation of a Film-Cooled

Turbine Vane", Journal of Turbomachinery, Vol. 122, pp. 348-359.

Holmer, M.-L., Eriksson, L.-E., and Sunden, B., 2000, "Heat

Transfer on a Film Cooled Inlet Guide Vane", Proceedings of the ASME

Heat Transfer Division, HTD-Vol. 366-3, pp. 43-50.
Hunter, S. D., 1998, "Source Term Modeling of Endwall Cavity Flow Effects on Gaspath Aerodynamics in an Axial Flow Turbine", Ph.D. Thesis, U. of Cincinnati.

Leylek, J. H., and Zerkle, R. D., 1994, "Discrete-Jet Film Cooling: A Comparison of Computational Results With Experiments", Journal of Turbomachinery, Vol. 116, pp. 358-368.

Menter, F. R., 1993, "Zonal Two-Equation k- $\omega$ Turbulence Models for Aerodynamic Flows", AIAA Paper 93-2906.

Pedersen, D. R., Eckert, E. R. G., and Goldstein, R. J., 1977, "Film Cooling With Large Density Differences Between the Mainstream and the Secondary Fluid Measured by the Heat-Mass Transfer Analogy", Journal of Heat Transfer, Vol. 99, pp. 620-627.

Pietrzyk, J. R., 1989, "Experimental Study of the Interaction of Dense Jets With a Crossflow for Gas Turbine Applications", Ph. D. Dissertation, University of Texas at Austin.

Pietrzyk, J. R., Bogard, D. G., and Crawford, M. E., 1989 , "Hydrodynamic Measurements of Jets in Crossflow for Gas Turbine Film Cooling Applications", Journal of Turbomachinery, Vol. 111, pp. 139. 145 .

Pietrzyk, J. R., Bogard, D. G., and Crawford, M. E., 1990, "Effects of Density Ratio on the Hydrodynamics of Film Cooling", Journal of Turbomachinery, Vol. 112, pp. 437-443.

Rigby, D. L., 1996, "Method of Weakest Descent for Automatic Block Merging", $15^{\text {th }}$ International Conference on Numerical Methods in Fluid Dynamics, Monterey, CA, June 1996.

Rigby, D. L., Ameri, A. A., and Steinthorsson, E., 1997, 'Numerical Prediction of Heat Transfer in a Channel with Ribs and Bleed", ASME Paper 97-GT-431.

Schlichting, H., 1979, Boundary Layer Theory, McGraw-Hill, New York, $7^{\text {th }}$ edition, pp. 312-313.

Sinha, A. K., Bogard, D. G., and Crawford, M. E., 1991, "FilmCooling Effectiveness Downstream of a Single Row of Holes With Variable Density Ratio", Journal of Turbomachinery, Vol. 113, pp. 442449.

Steinthorsson, E., Liou, M.-S., and Povinelli, L. A., 1993, "Development of an Explicit Multiblock/Multigrid Flow Solver for Viscous Flows in Complex Geometries", AIAA Paper 93-2380.

Wilcox, D. C., 1994a, Turbulence Modeling for CFD, DCW Industries, Inc., LaCanada, CA.

Wilcox, D. C., 1994b, "Simulation of Transition With a TwoEquation Turbulence Model", AIAA Journal, Vol. 32, No. 2, pp. 247255. 


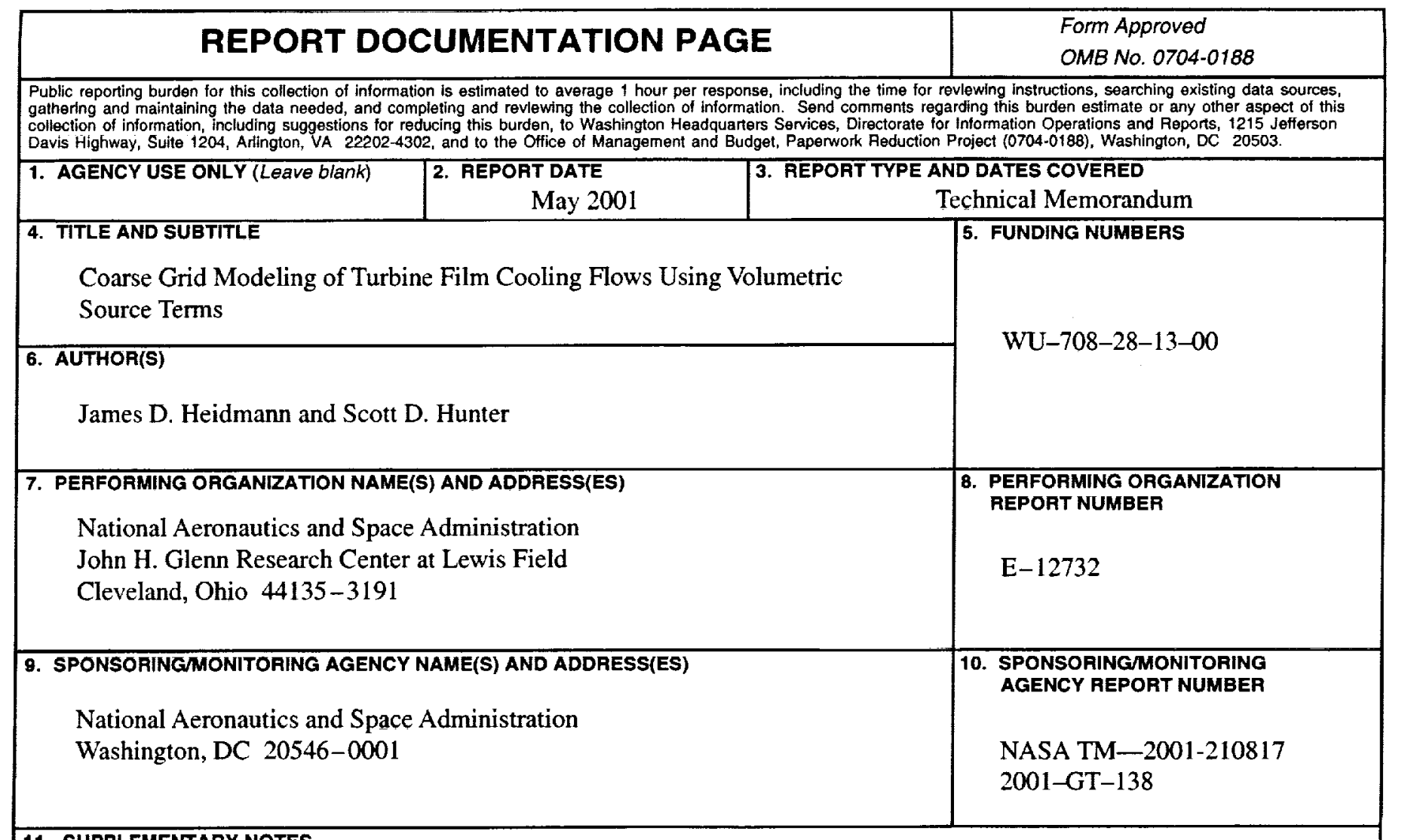

11. SUPPLEMENTARY NOTES

Prepared for the 2001 Turbo Expo sponsored by the American Society of Mechanical Engineers, New Orleans, Louisiana, June 4-7, 2001. James D. Heidmann, NASA Glenn Research Center, and Scott D. Hunter, General Electric Aircraft Engines, Evendale, Ohio 45215. Responsible person, James D. Heidmann, organization code 5820, 216-433-3604.

12a. DISTRIBUTION/AVAILABILITY STATEMENT 12b. DISTRIBUTION CODE

Unclassified - Unlimited

Subject Categories: 02, 07 and 34

Distribution: Nonstandard

Available electronically at http:/gltrs.grc.nasa.gov/GLTRS

This publication is available from the NASA Center for AeroSpace Information, 301-621-0390.

13. ABSTRACT (Maximum 200 words)

The recent trend in numerical modeling of turbine film cooling flows has been toward higher fidelity grids and more complex geometries. This trend has been enabled by the rapid increase in computing power available to researchers. However, the turbine design community requires fast turnaround time in its design computations, rendering these comprehensive simulations ineffective in the design cycle. The present study describes a methodology for implementing a volumetric source term distribution in a coarse grid calculation that can model the small-scale and three-dimensional effects present in turbine film cooling flows. This model could be implemented in turbine design codes or in multistage turbomachinery codes such as APNASA, where the computational grid size may be larger than the film hole size. Detailed computations of a single row of $35^{\circ}$ round holes on a flat plate have been obtained for blowing ratios of $0.5,0.8$, and 1.0, and density ratios of 1.0 and 2.0 using a multiblock grid system to resolve the flows on both sides of the plate as well as inside the hole itself. These detailed flow fields were spatially averaged to generate a field of volumetric source terms for each conservative flow variable. Solutions were also obtained using three coarse grids having streamwise and spanwise grid spacings of $3 \mathrm{~d}, 1 \mathrm{~d}$, and $\mathrm{d} / 3$. These coarse grid solutions used the integrated hole exit mass, momentum, energy, and turbulence quantities from the detailed solutions as volumetric source terms. It is shown that a uniform source term addition over a distance from the wall on the order of the hole diameter is able to predict adiabatic film effectiveness better than a near-wall source term model, while strictly enforcing correct values of integrated boundary layer quantities.

\begin{tabular}{|c|c|c|}
\hline \multicolumn{3}{|l|}{$\begin{array}{l}\text { 14. SUBJECT TERMS } \\
\text { Turbine; Film cooling }\end{array}$} \\
\hline $\begin{array}{l}\text { 17. SECURITY CLASSIFICATION } \\
\text { OF REPORT } \\
\text { Unclassified }\end{array}$ & $\begin{array}{l}\text { 18. SECURITY CLASSIFICATION } \\
\text { OF THIS PAGE } \\
\text { Unclassified }\end{array}$ & $\begin{array}{l}\text { 19. SECURITY CLASSIFICATION } \\
\text { OF ABSTRACT } \\
\text { Unclassified }\end{array}$ \\
\hline
\end{tabular}

